\title{
Ultrasonic Investigation of Elastic Anomalies in Lithium Sodium Sulphate Hexahydrate
} Single Crystal

\author{
George Varughese ${ }^{1}$, Santhosh Kumar ${ }^{2}$ \\ ${ }^{1}$ Department of Physics, Catholicate College, Pathanamthitta, India \\ ${ }^{2}$ SPAP, Mahatma Gandhi University, Kottayam, India \\ Email: gvushakoppara@yahoo.co.in
}

Received 22 July 2014; revised 15 August 2014; accepted 9 September 2014

Copyright (C) 2014 by authors and Scientific Research Publishing Inc.

This work is licensed under the Creative Commons Attribution International License (CC BY). http://creativecommons.org/licenses/by/4.0/

(c) (i) Open Access

\section{Abstract}

An extensive study of the thermal properties of Lithium Sodium Sulphate Hexa hydrate (LSSW) single crystal, with Trigonal structure, has been carried out using ultrasonic Pulse Echo Overlap (PEO) technique, Differential Thermal Analysis (DTA) and Thermo Gravimetric Analysis (TGA). The temperature variation of elastic constants of $\mathrm{LiNa}_{3}\left(\mathrm{SO}_{4}\right)_{2} \cdot 6 \mathrm{H}_{2} \mathrm{O}$ single crystal have been reported for the first time. The second order elastic stiffness constants $C_{11}, C_{33}, C_{44}$, along the various directions in the crystal have been determined in the temperature range $300-330 \mathrm{~K}$. The change in velocity with temperature with respect to the room temperature value has been measured using PEO technique. Significant anomalies were observed in $C_{11}$ and $C_{33}$ at $316 \mathrm{~K}$. The elastic constant $C_{12}$ has shown no variation in the temperature range 300 - $319 \mathrm{~K}$. A minor deviation for $C_{44}$ at $305 \mathrm{~K}$ following a parabolic change has been observed. The minor anomalies observed in the elastic constants of LSSW may be due to its dehydration of water of crystallization in the range 304 - $319 \mathrm{~K}$. DTA studies showed an appreciable endothermic change in the range 309 $\mathrm{K}-369.79 \mathrm{~K}$. TGA curve exhibited a decrease in weight of $1.687 \mathrm{mg}$ in the temperature range 304 $\mathrm{K}-360 \mathrm{~K}$. The minor anomalies observed in the elastic constants of LSSW may be due to loosing of its water of crystallization in the range 309 - $319 \mathrm{~K}$. On loosing water there will not be any change in chemical structure but there will be physical change associated with loosing of water molecule.

\section{Keywords}

Ultrasonics, Single Crystal, Elastic Properties, Pulse Echo Overlap Technique 


\section{Introduction}

Lithium Sodium Sulphate single crystal is an extensively studied super ionic crystal, which exhibits piezoelectric and pyro-electric properties. It is also non-centrosymmetric. In this family a new crystal $\mathrm{LiNa}_{3}\left(\mathrm{SO}_{4}\right)_{2} \cdot 6 \mathrm{H}_{2} \mathrm{O}$ (LSSW) is synthesized. This new sulphate salt characterized by the presence of water molecule in the unit cell, and it was reported [1]. The crystal structure was examined by X ray diffraction (XRD) pattern and compared it with Joint Committee Powder Diffraction Scan (JCPDS) file [2]. The crystal belongs to space group $C_{3 v}^{6}$ with 6 molecules per unit cell, Trigonal in symmetry and lattice parameters $a=b=8.451 \AA$ and $c=30.28 \AA$. The Fourier Transform Infrared spectrum (FTIR) of a sample is highly characteristic and hence it is widely used to identify substances. The presence of hydroxyl $[\mathrm{OH}]$ in the sample was confirmed by group in the FTIR spectrum of the sample [3]. Raman studies already reported in the literature have investigated phase transition in the temperature range $12 \mathrm{~K}$ - $300 \mathrm{~K}$. They haven't noticed any anomalies in that range of temperature [1]. For each site of $\mathrm{Li}^{+}$ion, there are two ions bound to three oxygen atoms of three different water molecules and an oxygen atom of the sulfates producing a perfect tetrahedron. There are 4 hydrogen bonds formed by water molecule with the oxygen atom of $\mathrm{SO}_{4}^{2-}$ and $\mathrm{LiO}_{4}^{2-}$ ions, namely 1) One connecting the oxygen of the $\mathrm{H}_{2} \mathrm{O}$ molecule to the top oxygen of the $\mathrm{SO}_{4}^{2-}$ tetrahedron; 2) Another connecting the oxygen of the $\mathrm{H}_{2} \mathrm{O}$ molecule to the top oxygen of the $\mathrm{LiO}_{4}^{2-}$ tetrahedron and 3) the remaining two are connecting the oxygen of the $\mathrm{H}_{2} \mathrm{O}$ molecule only to the base oxygen of the $\mathrm{SO}_{4}^{2-}$ tetrahedron. No investigation on phase transition has been conducted so far in the above room temperature range by any other method. Hence aim of this investigation is to investigate any anomalies in the elastic properties of the crystal by studying the variation of elastic properties of LSSW with temperature by ultrasonic Pulse Echo Overlap technique [4].

\section{Experimental}

\subsection{Sample Preparation}

$\mathrm{Li}_{2} \mathrm{CO}_{3}$ and $\mathrm{NaHSO}_{4} \cdot \mathrm{H}_{2} \mathrm{O}$ was mixed in equi molar ratio in triply distilled water. Large single crystals can be grown by Slow evaporation technique for a duration of 60 days. At $308 \mathrm{~K}$ Lithium Sodium Sulphate Hexahydrate crystal (LSSW) and at 323 K Lithium Sodium Sulphate single crystal were synthesized (LSS). The optical quality of the crystal can be enhanced by re-crystallization from the solution for several times, and with the usage of triply distilled water. Temperature of the bath is kept constant by using an efficient temperature controller having $0.5 \mathrm{~K}$ stability. Powder XRD of these crystals has been reported [3]. Size of the grown single crystal LSSW was $(30 \times 30 \times 25) \mathrm{mm}^{3}$ and depicted in Figure 1 . The natural faces of the sample have been identified by comparing the measured interfacial angles and the computed stereographic projection of the crystal planes. The stereographic net of the crystal about $a$ - and $c$-axes are made with the help of the computer programme "Jcrystal" by giving the values of lattice parameters, crystal system and space group of the crystal [5]. Bulk samples have been cut using a slow speed diamond wheel saw so as to have propagation direction along [100] and [001] axes of the crystal [6]. The cuttings are made very accurately and the mis-orientation in cutting is less than $1^{\circ}$. The thickness of the sample crystals along the measurement direction are in the range $0.8-1.2 \mathrm{~cm}$. The samples are well polished by using water paper of grade 1500 and Cerium oxide powder. This enables one to get proper bonding of transducer.

\subsection{Ultrasonic Velocity Measurements}

A Rhombohedral crystal has three-fold axis of symmetry and three mirror planes. The expression for the velocity of elastic waves in different symmetry directions are derived. It is found that $C_{11}=C_{22}, C_{33}, C_{44}=C_{55}, C_{12}$ and $C_{14}$ can be obtained by measuring the velocity in $c$-direction (three fold symmetry axis) and any one of the three axes in the base plane normal to a mirror plane and the third pure mode axis in the $m_{1}$ plane. The sixth elastic constant $C_{13}=C_{23}$ can be found by velocity measurement of quasi-longitudinal wave in a mirror plane at $45^{\circ}$ with $c$-axis. The elastic constant $C_{66}$ can be obtained by knowing $C_{11}$ and $C_{12}$ by the relation [4]. $C_{66}=1 / 2\left[C_{11}-C_{12}\right]$. The mirror planes are depicted in Figure 2.

The elements of determinantal equation are defined by elastic constants and the direction cosines of the direction of propagation [6]. Non zero elastic constants are shown in the detrmininent. 


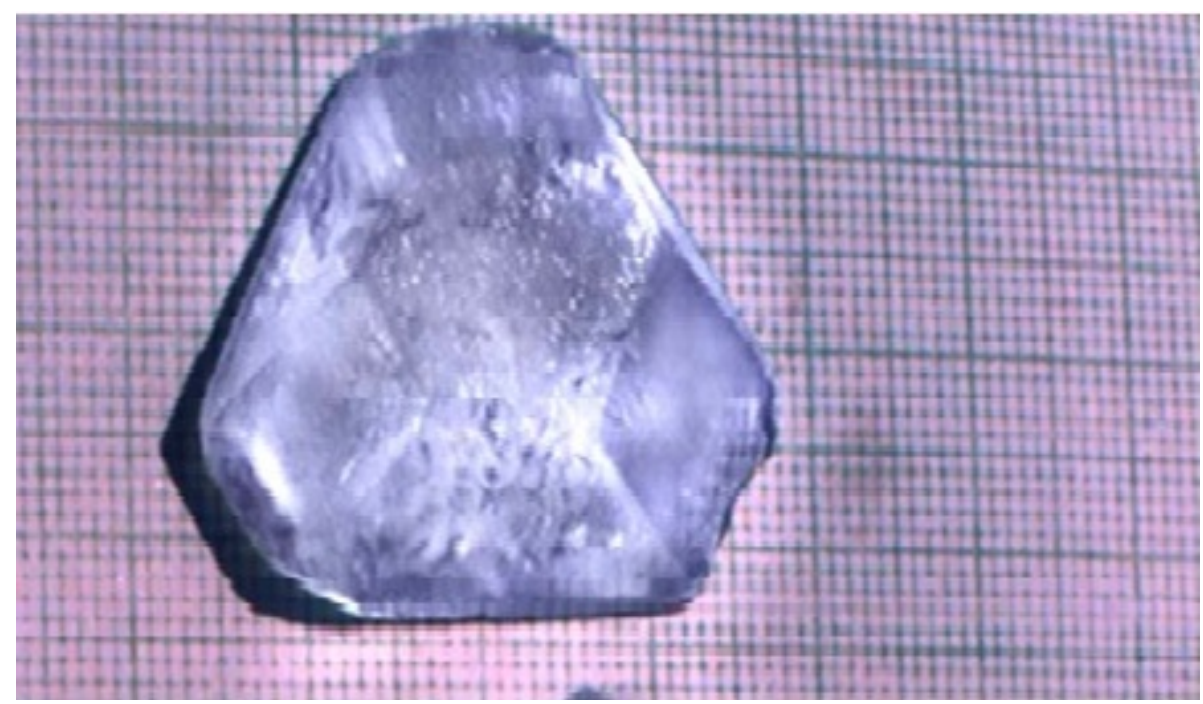

Figure 1. Grown crystal of Lithium Sodium Sulphate Hexahydrate (LSSW).

$$
\left|\begin{array}{cccccc}
C_{11} & C_{12} & C_{13} & C_{14} & 0 & 0 \\
0 & C_{22} & C_{23} & 0 & 0 & 0 \\
0 & 0 & C_{33} & 0 & 0 & 0 \\
0 & C_{24} & 0 & C_{44} & 0 & 0 \\
0 & 0 & 0 & 0 & C_{55} & C_{56} \\
0 & 0 & 0 & 0 & 0 & C_{66}
\end{array}\right|=0
$$

Here $C_{13}=C_{23}, C_{14}=-C_{24}, C_{56}=2 C_{14}$.

If the cosines and the velocity in crystallographic directions are known, the adiabatic elastic constants can be determined [3]. The velocity of ultrasonic waves was measured for ultrasonic longitudinal and transverse waves in the specimen using $X$ and $Y$ cut transducer. The measurement was carried out by using Pulse Echo Overlap technique [PEO] [7] [8]. Silicon grease was used as the coupling medium between the transducer and the crystal. A MATEC model 7700 pulse modulator and receiver system with its associated subunits have been used for the velocity measurements.

The McSkimin $\Delta t$ criterion [5] [9]-[11] has been applied to correct for the phase lag introduced by the coupling medium on the RF echoes. Crystal system of Lithium Sodium Sulphate Hexahydrate is Trigonal type II. It has the following six second order elastic stiffness constants $C_{11}=C_{22}, C_{33}, C_{44}=C_{55}, C_{12}, C_{14}$ and $C_{13}=C_{23}$ and $C_{66}=1 / 2\left(C_{11}-C_{12}\right)$ [6] [9]. The diagonal elastic constants $C_{11}, C_{33}, C_{44}$ have direct relationship with the suitable ultrasonic mode velocity given by $C_{i j}=\rho v^{2}$ where $\rho$ is the density of the crystal and $v$ is the velocity of ultrasonic waves through the crystal. The absolute accuracy of elastic constant value is $0.2 \%$ for diagonal elastic constant and $1 \%$ for off diagonal elastic constants. The off diagonal elastic stiffness constants can be evaluated by using the equations reported in the literature [6].

$$
\begin{gathered}
f_{a b^{*}}=C_{14}=1 / 2\left\{\left[2 \rho v_{1}^{2}-\left(C_{66}+C_{44}\right)\right]^{2}-\left(C_{66}-C_{44}\right)^{2}\right\}^{1 / 2}, \\
f_{a b}=C_{12}=C_{11}+2 C_{44}-2\left(\rho v_{1}^{2}+\rho v_{2}^{2}\right), \\
f_{a c}=C_{13}=\frac{1}{n_{3} n_{1}}\left\{\left[\frac{C-\left(m^{3}-m^{2} A+m B\right)}{D}\right]\right\}^{\frac{1}{2}}-C_{44} .
\end{gathered}
$$

Here, 


$$
\begin{gathered}
C_{11} n_{1}^{2}+C_{44} n_{3}^{2}=a \\
C_{66} n_{1}^{2}+C_{44} n_{3}^{2}=b \\
C_{44} n_{1}^{2}+C_{33} n_{3}^{2}=c \\
2 C_{14} n_{1} n_{3}=l \rho v^{2}=m
\end{gathered}
$$

where $n_{1}=1 / \sqrt{ } 2, \quad n_{3}=1 / \sqrt{ } 2$

$$
\begin{gathered}
a+b+c=A \\
a b+b c+a c-l^{2}=B \\
a b c-c l^{2}=C \\
(a-b-2 l)=D
\end{gathered}
$$

Here, $n_{3}=\cos \theta, n_{1}=\sin \theta$, and $\theta$ is measured from $c$ axis and $\theta=45^{\circ}$.

\subsection{Variation of $C_{i j}^{s}$ with Temperature}

The temperature variation of $C_{i j}^{s}$ along the various directions in the crystal have been determined in the high temperature range 300 - $330 \mathrm{~K}$ by keeping the sample mounted on a suitable holder in a temperature controlled chamber. The change in velocity with temperature with respect to the room temperature has been measured carefully by adjusting the CW oscillator frequency of PEO system. Keeping the selected RF echoes in the phase matched condition the accuracy of the relative measurements of velocity is of the order of $10^{-5}$. The rate of temperature change in all the measurements are in the range of 0.5 to $1 \mathrm{~K}$ per minute. Here we have carried out the temperature variation of four elastic constants $C_{11}, C_{33}, C_{44}, C_{12}$. The variation of elastic constants with temperature is as shown in [Figure 3 and Figure 4]. We could not investigate beyond $330 \mathrm{~K}$ because of the opaqueness developed in the crystal. This may be due to the exclusion of water molecule associated with the grown crystal. The thermal expansion has been neglected while measuring the variation of ultrasonic wave velocities with temperature.

\subsection{Differential Thermal Analysis (DTA) \& Thermo Gravimentric Analysis (TGA) Spectrum of LSSW}

The DTA and TGA scans have been depicted in Figure 5. An appreciable endothermic dip at $369.79 \mathrm{~K}$. There

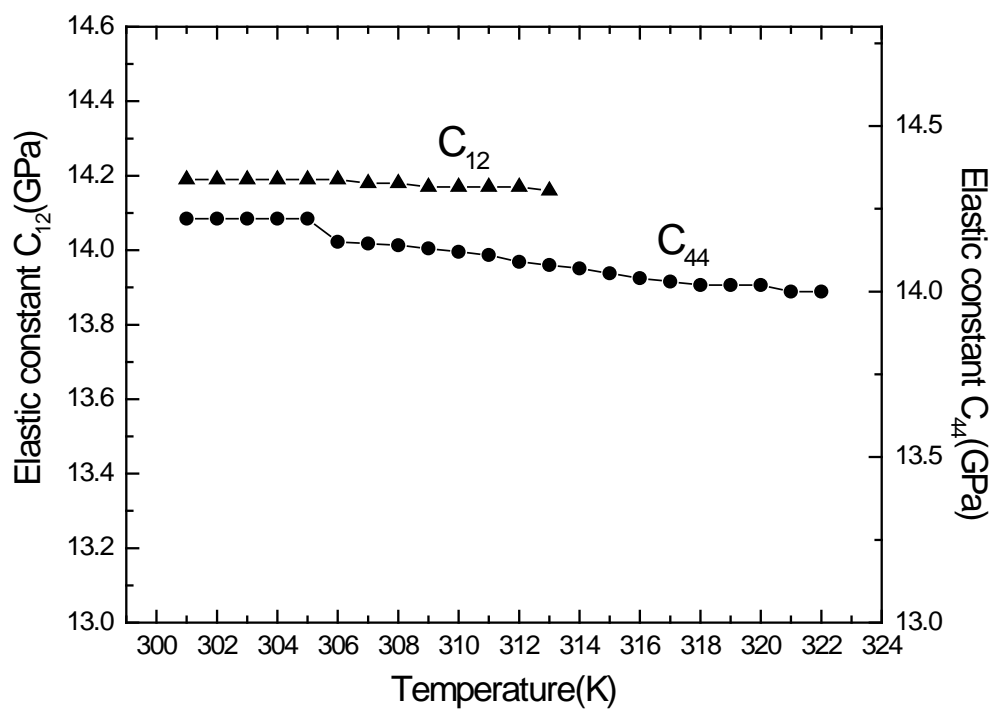

Figure 2. Variation of elastic constants $C_{12}$ and $C_{44}$ with temperature. 


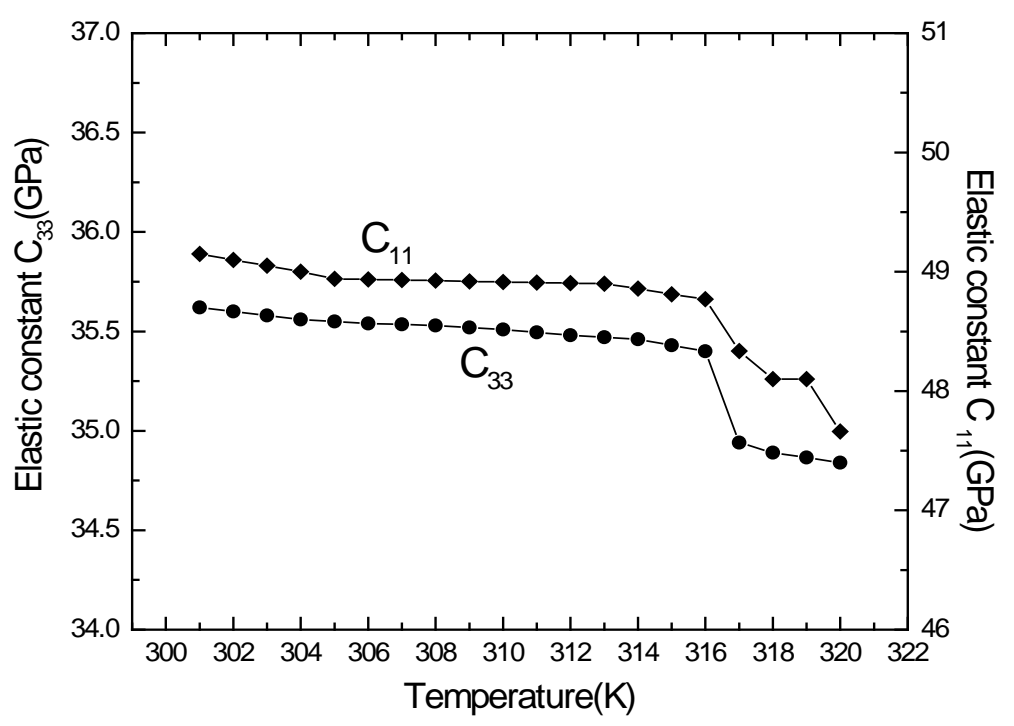

Figure 3. Variation of elastic constants $C_{11}$ and $C_{33}$ with temperature.

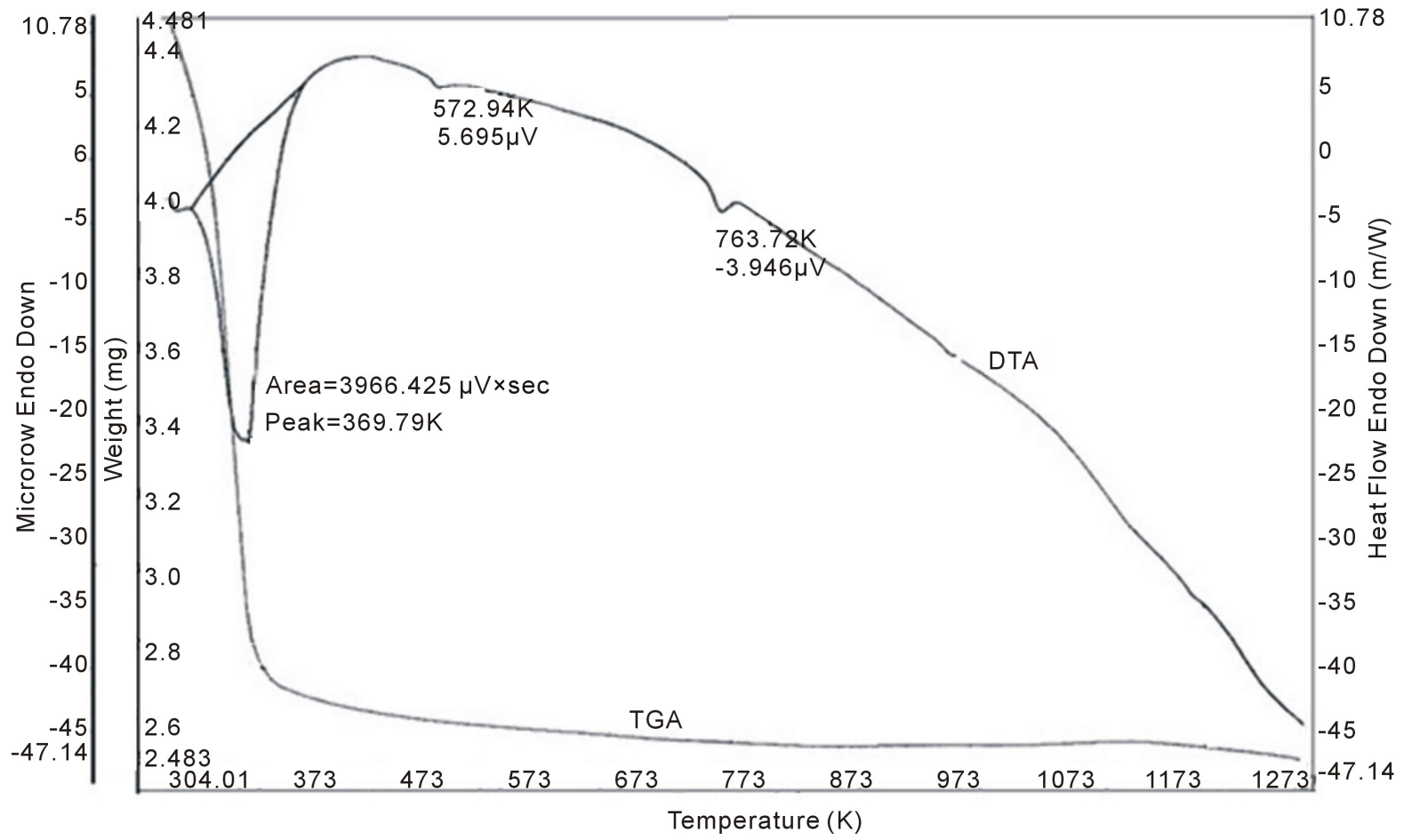

Figure 4. Differential Thermal Analysis and Thermo Gravimetric spectra of LSSW.

are also two small dips at $526.62 \mathrm{~K}$ and $765.04 \mathrm{~K}$. The energy associated with the transition can be evaluated [12] from area enclosed by dip. The peak areas in differential thermo grams depend upon the mass of the sample, “m”, and enthalpy/unit mass is $\Delta H$ (energy associated with the transition). These variables are related by the equation

$$
A=-k G m \Delta H
$$

where " $A$ " is the area of the peak, " $G$ " is a calibration factor that depends on geometry, " $k$ " is a constant related to the thermal conductivity of the sample. The energy associated with the transition of the sample is estimated as $2.566 \mathrm{~J} / \mathrm{g}$. TGA curve exhibited a decrease in weight in the temperature range $304 \mathrm{~K}-360 \mathrm{~K}$. The re- 
duction in mass occurred is $1.687 \mathrm{mg}$ in the temperature range $304 \mathrm{~K}-373 \mathrm{~K}$. The weight loss may be due to vaporization of water molecules present in the crystal.

\section{Results and Discussions}

For the Trigonal class system, there are six elastic constants $C_{11}=C_{22}, C_{33}, C_{44}=C_{55}, C_{12}, C_{14}$ and $C_{13}=C_{23}$. Starting with the well known Christoffel equation, one can deduce the relationship between the elastic constants. Velocity of propagation of various ultrasonic modes measured along selected direction in the crystal is listed in Table 1. These measurements enabled to measure six elastic constants [3]. Temperature variations of four second order elastic stiffness constants $C_{11}, C_{33}, C_{44}, C_{12}$ have been carried out. Significant anomalies were observed in $C_{11}$ and $C_{33}$ at $316 \mathrm{~K}$. The elastic constant $C_{12}$ has shown no variation in the temperature range $300-319 \mathrm{~K}$. A minor deviation for $C_{44}$ at $305 \mathrm{~K}$ following a parabolic change has been observed. The minor anomalies observed in the elastic constants $C_{11}, C_{33}, C_{44}$ of LSSW may be due to its dehydration of water of crystallization in the range $304-319 \mathrm{~K}$. The shape of the curves is shown in Figure 2 and Figure 3. One could not investigate beyond $330 \mathrm{~K}$ because of the opaqueness developed in the crystal. This may be due the exclusion of water molecule associated with the crystal between $316 \mathrm{~K}$ and $320 \mathrm{~K}$.

\section{Conclusion}

The structural discrepancies found in the crystal grown at $323 \mathrm{~K}$ and $308 \mathrm{~K}$ have been solved to an extent using the ultrasonic velocity measurements. Temperature variations of four second order elastic stiffness constants $C_{11}, C_{33}, C_{44}, C_{12}$ have been carried out. Noteworthy anomalies were observed in $C_{11}$ and $C_{33}$ at $316 \mathrm{~K}$. The elastic constant $C_{12}$ has shown no variation in the temperature range 300 - $319 \mathrm{~K}$. A minor variation for $\mathrm{C}_{44}$ at $305 \mathrm{~K}$ following a parabolic change has been observed. Hence one can presume that the minor anomalies observed in the elastic constants of LSSW may be due to loosing of its water of crystallization in the range 304 $319 \mathrm{~K}$. On loosing water there will not be any change in chemical structure but there will be physical change

Table 1. Velocity of ultrasonic modes in LSSW at $300 \mathrm{~K}$. L, T, QL, QT represent longitudinal, transverse, quasi-longitudinal and quasi transverse modes respectively. The relations between mode velocities and elastic constant are also given in [3].

\begin{tabular}{|c|c|c|c|c|c|}
\hline Mode & $\begin{array}{l}\text { Direction of } \\
\text { propagation }\end{array}$ & $\begin{array}{l}\text { Direction of } \\
\text { polarization }\end{array}$ & $\begin{array}{l}\text { Measured mode } \\
\text { velocity }(\mathrm{m} / \mathrm{s})\end{array}$ & $\begin{array}{l}\text { Velocity-Elastic } \\
\text { constant relation }\end{array}$ & $\begin{array}{l}\text { Elastic constants } \\
\text { (GPa) }\end{array}$ \\
\hline $\mathrm{L}$ & {$[100]$} & {$[100]$} & $v_{1}=4769 \pm 4$ & $C_{11}=C_{22}=\rho v_{1}^{2}$ & $C_{11}=C_{22}=45.84 \pm 0.09$ \\
\hline $\mathrm{T}$ & {$[100]$} & [001] & $v_{2}=2592 \pm 2$ & $C_{12}=f_{a b}\left(v_{2} \& v_{3}\right)$ & $C_{12}=15.3 \pm 0.33$ \\
\hline $\mathrm{T}$ & {$[100]$} & [001 \& 010] & $v_{3}=2628 \pm 2$ & $C_{14}=f_{a b^{*}}\left(v_{3}\right)$ & $C_{14}=0.648 \pm 0.19$ \\
\hline $\mathrm{L}$ & {$[001]$} & {$[001]$} & $v_{4}=4808 \pm 4$ & $C_{33}=\rho v_{4}^{2}$ & $C_{33}=46.60 \pm 0.09$ \\
\hline $\mathrm{T}$ & {$[001]$} & {$[001]$} & $v_{5}=2460 \pm 2$ & $C_{44}=C_{55}=\rho v_{5}^{2}$ & $C_{44}=C_{55}=12.21 \pm 0.02$ \\
\hline QL & $\begin{array}{l}\text { Along mirror } \\
\text { Plane } 45^{\circ} \text { to } \\
C \text {-axis }\end{array}$ & QL & $v_{6}=4571 \pm 4$ & $C_{13}=f_{a c}\left(v_{6}\right)$ & $C_{13}=2.54 \pm 1.2$ \\
\hline
\end{tabular}

where $C_{12}=f_{a b}, C_{14}=f_{a b}^{*}, C_{13}=f_{a c}$ and $C_{66}=1 / 2\left(C_{11}-C_{12}\right)=15.27 \pm 0.03$.

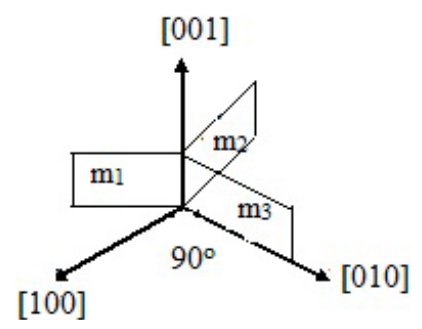

Figure 5. Symmetry axis and mirror planes of Trigonal crystals. 
associated with loosing of water molecule. Differential Thermal Analysis Scan showed a large endothermic dip during the range $309 \mathrm{~K}-369.79 \mathrm{~K}$. The energy associated with the sample is estimated as $2.566 \mathrm{~J} / \mathrm{g}$. Thermo Gravimetric Analysis curve exhibited a reduction in mass of $1.687 \mathrm{mg}$ in the temperature range $304 \mathrm{~K}-373 \mathrm{~K}$.

\section{Acknowledgements}

The author (G.V.) is grateful to UGC Delhi for a Teacher Fellowship.

\section{References}

[1] Filho, J.M., Paiva, R.O., Freire, P.T.C. and Melo, F.E. (1999) X-Ray and Temperature Polarized Raman Spectroscopic Characterization of the $\mathrm{LiNa}_{3}\left(\mathrm{SO}_{4}\right)_{2} \cdot 6 \mathrm{H}_{2} \mathrm{O}$ Crystal. Journal of Raman Spectroscopy, 30, 289. http://dx.doi.org/10.1002/(SICI)1097-4555(199904)30:4<289::AID-JRS375>3.0.CO;2-F

[2] JCPDS File Card No. 712172.

[3] George, V., Kumar, A.S. and Louis, G. (2009) Anisotropy in Elastic Properties of Lithium Sodium Sulphate Hexa Hydrate Single Crystal—An Ultrasonic Study. Bulletin of Materials Science, 32, 621. http://dx.doi.org/10.1007/s12034-009-0096-7

[4] Papadakis, E.P. (1967) Ultrasonic Pulse Velocity by the Pulse-Echo Overlap Method Incorporating Diffraction Phase Correlation. The Journal of the Acoustical Society of America, 42, 1045. http://dx.doi.org/10.1121/1.397777

[5] Godfrey, L. and Philip, J. (1994) Elastic Constants and High Temperature Anomalies Near 425 K in Lithium Hydrazeniumsulphate. Journal of Applied Physics, 75, 2393. http://dx.doi.org/10.1063/1.356260

[6] Truell, R., Elbaum, C. and Chick, B.B. (1969) In: Ultrasonic Methods in Solid State Physics, Academic Press, New York, 370 .

[7] McSkimin, H.J. (1964) In: Mason, W.P., Ed., Physical Acoustics, Part A, Academic Press, New York, Vol. I, 271.

[8] Papadakis, E.P. (1976) Ultrasonic Velocity and Attenuation: Measurement Methods with Scientific and Industrial Applications. In: Mason, W.P. and Thurston, R.N., Eds., Physical Acoustics, Academic Pressm New York, Vol. XII, 227.

[9] Nye, N.F. (1957) Physical Properties of Crystals. Oxford University Press, London, 145.

[10] May Jr., J.E. (1958) Circuit Theory; Ultrasonic Engineering. IRE.Natl.Conv.Rec., 6, Part 2, 134.

[11] McSkimin, H.J. (1961) Pulse Superposition Method for Measuring Ultrasonic Wave Velocities in Solids. The Journal of the Acoustical Society of America, 33, 12. http://dx.doi.org/10.1121/1.1908386

[12] Skoog, D.A., Holler, F.J. and Nieman, T.A. (1997) In: Principles of Instrumental Analysis, Harcourt Asia PTE Ltd., Singapore. 
Scientific Research Publishing (SCIRP) is one of the largest Open Access journal publishers. It is currently publishing more than 200 open access, online, peer-reviewed journals covering a wide range of academic disciplines. SCIRP serves the worldwide academic communities and contributes to the progress and application of science with its publication.

Other selected journals from SCIRP are listed as below. Submit your manuscript to us via either submit@scirp.org or Online Submission Portal.
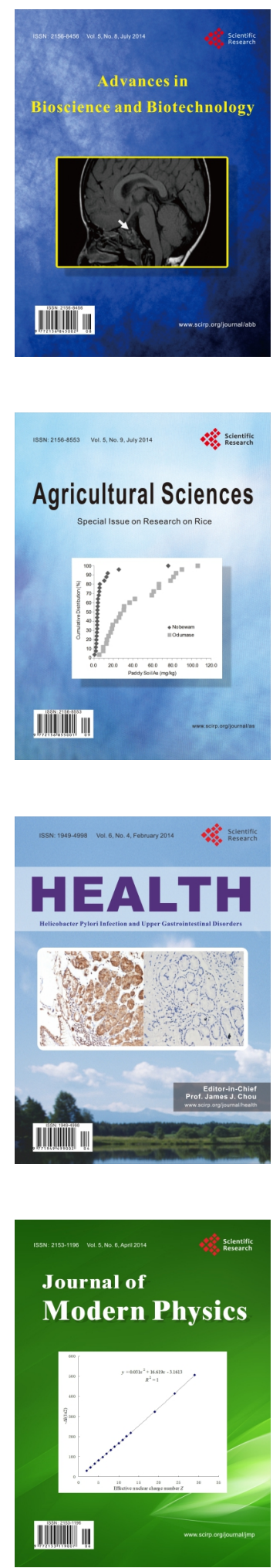
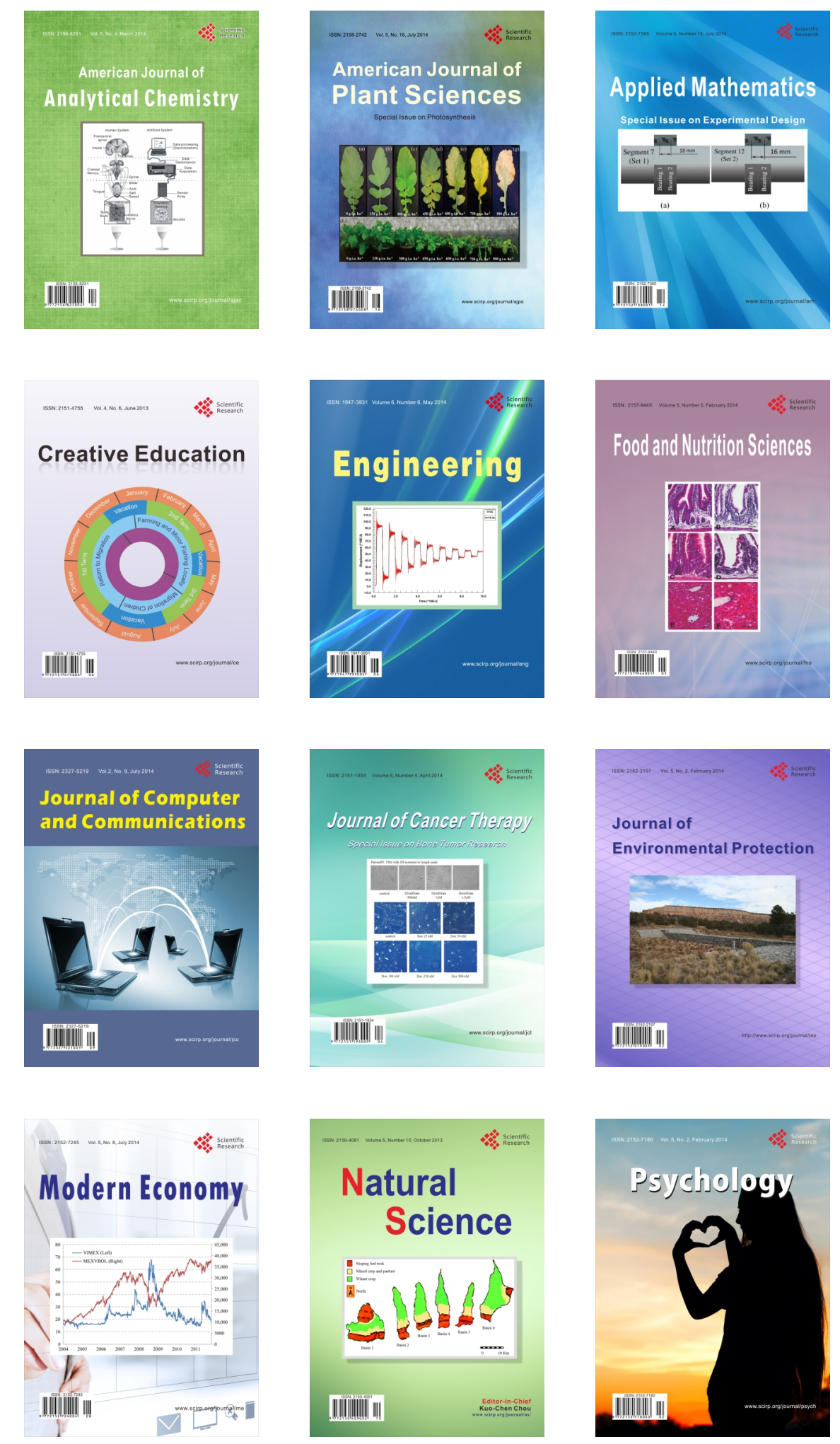